\title{
Research on Network Anonymity in the Context of New Media-From the Perspective of the Anonymous Expression of Chinese College Students in QQ Group
}

\author{
Huang Yi-ning, Yang Xi-xi \\ Central China Normal University, Wuhan, China
}

\begin{abstract}
This paper focuses on the characteristics of the anonymous expression by Chinese college students on Tencent QQ, which is one of the most popular new media among Chinese students. By analyzing the content of anonymous expression in one QQ group of college students and by interviewing the students involved, we found the activeness and heterogeneity of the subject as well as the concealment and particularity of anonymous expression. This paper further analyzes the reasons behind these characteristics, including the objective environment of new media, removal of responsibility in anonymous expression and conformity in an enclosed space. This paper aims to reveal how anonymous expressions operate in the context of new media.
\end{abstract}

Keywords: new media, network anonymity, anonymous expression in QQ group

\section{Introduction}

Anonymity has been a long-term research topic in the academic field. With Internet embedding deeply into daily life, anonymity has found its new expression in the context of new media and presented distinctive characteristics. Among various new media, Chinese QQ group is now one of the most important public platforms for Chinese college students to achieve real-time information dissemination and information exchange. Since 2014, when Tencent officially added anonymous chatting function to QQ group, the anonymous way of expression has become a significant channel for college students to vent emotions, show attitudes, or give suggestions.

\section{The Characteristics of the Anonymous Expression of Chinese College Students in QQ Group}

\section{The Activeness and Heterogeneity of the Subject}

Compared with other communication groups, college students are relatively more active on online platforms. According to China Statistical Report on Internet Development released by China Internet Network Information Center (CNNIC), about 25\% Internet users are students (2017, p. 15), which account for the largest proportion by the end of 2016. In addition, among these student groups, college student is a remarkable part. As a basic Internet application, instant messaging has reached the utilization rate of $91.1 \%$ of the total Internet

Huang Yi-ning, M.GA., School of Journalism and Communication, Central China Normal University.

Yang Xi-xi, undergraduate, School of Journalism and Communication, Central China Normal University. 
users (CNNIC, 2017, p. 24). And among all the instant messaging applications, QQ has the highest utilization rate of $79.4 \%$ (Zhao, 2014, p. 43), according to a research on the current situation of the use of mobile phone network among college students from four colleges in Chongqing.

Besides activeness, college students also show heterogeneity from person to person in the meantime. After analyzing the content of group chats, we found three dominant types of group members. The first is the impulse style, which is impetuous yet full of sense of justice. Once faced with unfair situations, this group of students would be easily irritated and would send provocative messages. The second is the rational type. They are well aware of what is right and what is not. And they have a good control of their own emotions, which makes themselves natural "peacemakers" whenever a contradiction or conflict appears. The third group consists of "onlookers," most of whom are introverted and moderate. They are more inclined to participate in the "peep screen party." And they merely wait and see, but never type a word. Moreover, individual differences appear even in the same group of personality type. Every student will be, to some extent, sensitive to a certain kind of information, and will have different levels or ways of responses towards a certain topic. For example, in the group of "peacemakers," some may set their mind on the possible solutions, some may prefer sending "chicken soup," and some may throw funny pictures to ease the tense atmosphere.

\section{The Concealment and Particularity of Anonymous Expression}

Different from real-name chatting, anonymous chatting allows users to send messages in the setting where other group members completely have no idea of the person behind a message. The original intention of having anonymous group chatting function in Tencent QQ (2014) is to "free users from the limitation of identity and express their own thoughts bravely in group chatting." To some extent, anonymous chatting indeed promises democracy and increases the pleasure of messaging in a group. On the other hand, it brings up certain problems as group members can say anything regardless of possible consequences, because anonymity conceals identities, and therefore, no responsibility is attached. Randi Jayne Zuckerberg, former Director of Market Development and spokesperson for Facebook once said, "People behave a lot better when they have their real names down. ... I think people hide behind anonymity and they feel like they can say whatever they want behind closed doors" (Gapper, 2011). That is how anonymous chatting brings out the natural instincts of a human being, which are usually controlled in real-name communication. With anonymous group chatting function, internet users express opinions and vent emotions as they want. Group chatting thus becomes a carnival for group members.

\section{Reasons for the Anonymous Expression of Chinese College Students in QQ Group}

\section{The Objective Environment of New Media}

Social anxiety is one of the complicated real-life causes for online anonymous expressions. One investigation conducted by the Questionnaire Center of People's Forum has shown that there are ten kinds of social morbidity in China, among which "social anxiety" ranks the top three (Xu, Yuan, \& Tan, 2014, pp. 19-20). Underneath the image of harmony lies a nervous and panic generation, college students are more inclined to feel stressed and strongly desire to achieve quick success and instant benefits. Therefore, they are desperate for a safe space where they can freely vent their emotions without getting any penalty. The president

\footnotetext{
${ }^{1}$ In this paper, "chicken soup" does not mean "soup made from chicken broth." Rather, it refers to words that can heal your emotional hurts and pains, similar to "chicken soup for the soul."
} 
of Peking University, Lin Jianhua admitted, "These years, Peking University has also emerged several problems as they are in the society. A few students seek quick success and instant benefits and they like to do grandiose things to impress people" (Zhou, 2015).

In addition to the widespread anxiety in the society, the campus that college students live in conceals different types and levels of real-life stimuli. They can be trivial in daily life matters, such as the electricity supply in dorms, food safety of the student canteen, or even a stray dog in living communities. It might also be essential information related to students' future career development, such as graduation practice, postgraduate application, and job hunting, which is much more likely to poke students in their sensitive nerves. Any adjustment or change can greatly affect their mood. Thus, they need a platform, either to clarify their stands or to let out their emotions.

\section{Removal of Responsibility in Anonymous Expression}

Anonymous chatting in QQ group conceals the identity and personal information of messengers, making them "dare" to speak. In real-life situation, the consolidation of role expectation and the formalization of the meaning system prevent individuals from controlling the external social entities (Zhang, 2003). Group members are too cautious to reveal their thoughts as it might ruin their public image. When using the anonymous identity to chat in QQ group, students hide their identity and hence manage to put down psychological baggage, such as concerns on personal image and pressure from other group members. Moreover, they are given the opportunity to voice out on the topics that are considered too sensitive to be discussed in real-life setup.

In anonymous situation, not merely do college students speak more freely, they also speak recklessly even irresponsibly. Anonymity is like a safe shelter to its users, and as a result, they tend to immerse themselves into a responsibility-decentralized mental state where their obedience toward social norms and group rules is reduced, and "anonymous uniform effect" "2 comes into play. At this point, the scale of the word used in group chatting is largely broadened to meet their emotional needs. By contrast analysis, we found radical words appear more frequently in the anonymous than the real-name situation. The psychological experiment by Niu Geng-feng (2015) had proved that Network anonymity will greatly reduce a man's attention on self-performance and outer evaluation. The threshold of constrained behavior will decrease as well, resulting in more extreme conduction and deviant behavior from social restriction.

\section{Conformity in an Enclosed Space}

QQ group is more private compared to other new media sharing platforms, such as Qzone and Weibo, because messages and topics are only shared among a certain number of members instead of mass audiences. Chatting in an enclosed space restricts the spread of a discussed topic and keep it within a limited sphere, as a result of which, the power of communication weakens horizontally making the topic hard to spread to more audiences, yet strengthens vertically bringing more insights or aspects into it.

In a private group chatting, individual reactions are greatly influenced by other members in the group. When the topic is focused and a number of people participate in the discussion, group assemblage in the virtual space comes into being. At first, when several speakers raise similar views or express similar emotions, the

\footnotetext{
${ }^{2}$ Anonymous uniform effect originated from the "simulated prison" experiment that the American psychologist Philip Pond Baldo did in 1973, which shows that when all the members of a group wear the same uniform, individuals are likely to be in a "responsibility-decentralized" condition, their sense of responsibility reduced for individual identities are hard to recognize in an anonymous environment.
} 
majority of the rest group members will be likely to tacitly regard them as opinions agreed by most people, therefore, they tend to resonate with them consciously or unconsciously. As is believed by the French social psychologist Jean Gabriel Tarde, everything in society is either invented or imitated (Ren, 2011). Therefore, limitation in a QQ group unifies views or emotions.

Group contagion also promotes conformity behavior. In QQ groups, obscure hint sources vary in different forms, such as words coming out from the popup, network emoji, pictures, or the atmosphere right at that moment. Due to the effect of group contagion, personal opinions are weakened or disintegrated and personal emotions are affected unconsciously. In the book The Crowd by Gustave Le Bon (1998), it was once written "An individual may be an educated man. But it is possible that he becomes an incult guy-An animal that is dominated by its instinct. He is out of his own control, wild and cruel, and sometimes will show primitive enthusiasm and heroism." In an enclosed group, such as QQ group, an individual can easily deviate from a rational road to an irrational one.

\section{Conclusion}

In the context of new media, anonymous expression has found a variety of new means of expression. This paper focused on the anonymous communication in QQ group of Chinese college students. We found that the characteristics of college students and anonymous expression mentioned above distinguish the anonymous group communication from real-name group communication. What we have further explored about the objective environment of new media, removal of responsibility in anonymous expression and conformity in an enclosed space can lay the foundation for future researches, such as solutions on the network public opinion event of college students, the coping strategy and management of college student emergencies. Therefore, these could possibly provide new ideas to improve the overall university administration system and promote the modernization of a university's governance ability.

\section{References}

China Internet Network Information Center. (2017). China statistical report on internet development. Retrieved February 18, 2017, from http://www.cnnic.net.cn/gywm/xwzx/rdxw/2016/201608/W020160803204144417902.pdf

Gapper, J. (2011). It is right to curtail web anonymity. The Financial Times. Retrieved February 18, 2017, from https://www.ft.com/content/f3637672-d31e-11e0-9ba8-00144feab49a

Gustave, L. B. (2010). The crowd (1st ed.). (G. N. Dai, Trans.). Beijing: The New World Press. (Original work published in 1998)

Niu, G. F., Zhou, Z. K., Sun, X. J., \& Fan, C. Y. (2015). Influence of network anonymity and peer network deviation behavior on college students' network deviation behavior: Regulating effect of self-control. Chinese Journal of Special Education, 22(11), 76.

Ren, X. M. (2011). Research on communicative behavior and its social influence in virtual community. Shandong: Shandong Normal University.

Tencent Customer Service. (2014). What's anonymous chatting? Retrieved February 18, 2017, from http://kf.qq.com/faq/120511jiYzIJ140910yyyYZz.html

Xu, Y. H., Yuan, J., \& Tan, F. (2014). Current social morbid investigation and analysis report. People's Tribune, 11(25), 19-20. doi: $10.16619 /$ j.cnki.rmlt.2014.25.028

Zhao, X. (2014). Investigation on the current situation of the use of mobile phone network among college students. E-Education Research, 34(4), 43. doi: 10.13811/j.cnki.eer.2014.04.007

Zhang, Z. Y. (2003). A preliminary study on network anonymity. China Youth Study, 15(12), 15.

Zhou, Z. J. (2015). Several presidents' discussion on Chinese university: A few people flatter themselves and the study environment is impetuous. Retrieved February 18, 2017,from http://www.thepaper.cn/newsDetail_forward_1393393 